\title{
Estudios Bibliográficos en Preparación
}

De acuerdo con lo aprobado en el Segundo Congreso del IILI, la Comisión de Bibliografía publicará anualmente, en la REvista IBEROAMERICANA, una lista de estudios bibliográficos en preparación. Debe entenderse que los titulos solamente son provisionales. Quedan incluídos artículos y libros de indole crítica, siempre que tengan bibliografías 'adjuntas. Con el fin de hacer esta lista más completa y por lo tanto más útil en la orientación de otros trabajos bibliográficos y críticos, se pide encarecidamente a los bibliógrafos que informen a la Comisión de Bibliografía acerca de los trabajos que tienen en preparación.

Armmage, R. H. - The Ideologies of Mauricio Magdaleno and Jorge Ferretis. Tesis de Maestro. Ohio State University. 1940.

Cuthbertson, S. - Historical anthology of Argentine literature.

DoYLE, H. G. - Central-American bibliography and Cuban-American literary relations.

Eason, Sarah M. - - Rubén Romero. Tesis de doctorado. Ohio State University. 1942.

EnglekrRK, J. E. - Adiciones a la bibliografía de Dario, obras originales de Dario y estudios críticos sacados principalmente de las revistas literarias de Colombia y la América Central. ,

- - Bibliografía de las traducciones, los estudios críticos y las imitaciones de autores norteamericanos hechos por hispanoamericanos.

___ - Bibliografía crítica de las revistas literarias de Chile, Colombia y la América Central. 
Los arriba citados formarán parte de libros y artículos en preparación.

García-Prada; Carlos. - Bibliografía de José Asunción Silva. Apéndice del libro Prosas y versos de J. A. S.

Grismer, R. L. - A new bibliography of the literatures. of Spain and Spanish America. Volumen III, en prensa.

The Hispanic foundation of the Libraky of Congress. - Recotd of investigations in progress in the U. S. A. in Latin American humanistic and social science studies.

JoNEs, C. K. - Bibliography of Latin American bibliographies. Libro. 1941.

Jones, W. K. - Bibliography of translations into English of Spanish American literary productions including poems, stories and plays. 1941. (?)

- - Study of Spanish American drama, including a list of $\mathrm{pu}^{-}$ blications not found_in the Harvard series.

LEAvirt, S. E., Nichols, M. W. y SPELL, J. R. - A bibliography of literary linguistic and folklore articles in the most important journals of Hispanic America.

Menéndez, Cardos R. - Para la historia del Imperio en Yúcatán. Libro en prensa. 1941.

- - Visiones de Mérida. La Emérita Peninsular a través de cuatro siglos. 1542-1942. Libro. 1942.

MooRe, E. R. - Bibliografía de catálogos de seudónimos y anónimos iberoameticanos. Artículo.

- - Bibliografía de novelistas mexicanos de la Revolución. Libro en prensa. 1941.

-_- Rafael Delgado: bio-bibliografia. Se publicará en México.

- Catálogo de seudónimos, iniciales y anónimos mexicanos. Libro. 1942.

- - Bibliografía de Martín Luis Guzmán. Artículo. 1941.

- - Indice de artículos literarios en revistas literarias mexicanas. Vol. I, hasta 1868. Vol. II, hasta 1900. 
MooRE, E. R.- Bibliografía de varios novelistas mexicanos del siglo XIX. —_- - Bibliografía del cuento y de la novela mexicanos.

- Adiciones a La Imprenta en México de J. T. Medina. 1a. parte: Siglo XVII. 2a. parte: Siglo XIX.

Nichors, Madaline W. - A bibliographical guide to materials on American Spanish. Libro en prensa. 1941.

- - Bibliographical articles on literatures of Spanish America. Bolivian and Central American near completion.

- - Bibliographical studies on Nosotros of Buenos Aires. Un artículo y un libro mimeografiado. 1941-42.

ReID, J. T. - Bibliografia de traducciones y crítica de literatura norteamericana en Hispanoamérica. Artículo. Enero de 1942.

- - Indice analitico de los articulos literarios del Repertorio Americano.

Rodrícuez Demorizl, EmIIo. - Bibliografía Dominicana, 1492-1941. Aparecerá de 1942 a 1943.

Schons, Dorotryy. - Bibliografía selecta de "Best Sellers" españoles. Libro. 1942.

- - Bibliografía de la prensa cubana. Aparece actualmente en la Revista Bibliográfica Cubana.

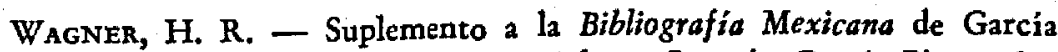
Icazbalceta. Traducido al español por Joaquin Garcia Pimentel y Federico Gómez de Orozco. En prensa en la Editorial Polis, México.

- - - Bibliografia e índice de la Biblioteca de Autores Mexicanos.

Wugus, A. C. - A list of novels in English and English translations for adults wich deal with Latin America or have a Latin American locale. Será impreso.en mimeógrafo por la Unión Panamericana.

- - - A list of articles relating to Latin America published in various geographical journals. Están terminados "Economic Geography" y "Journal of Geography".

- Studies on the historiography of Latin America. Para el Boletin de la Unión Panamericana. 
